\title{
Endoscopic management of difficult benign biliary and pancreatic strictures using a wire-guided cystotome: experience with 25 cases
}

(이요 $\ominus$

\author{
Authors \\ Rajesh Puri, Sumit Bhatia, Rinkesh K. Bansal, Randhir Sud \\ Institution \\ Institute of Digestive and Hepatobiliary Sciences, Medanta \\ The Medicity, Gurugram, India \\ submitted 21.2.2018 \\ accepted after revision 25.4 .2018 \\ Bibliography \\ DOI https://doi.org/10.1055/a-0624-2288 | \\ Endoscopy International Open 2018; 06: E797-E800 \\ (c) Georg Thieme Verlag KG Stuttgart · New York \\ ISSN 2364-3722 \\ Corresponding author \\ Dr. Rajesh Puri, Director, Institute of Digestive and \\ Hepatobiliary Sciences, Medanta The Medicity, Sector 38, \\ Gurgaon, Delhi NCR, India, PIN 122001 \\ Fax: +01244834111 \\ purirajesh70@gmail.com
}

\section{ABSTRACT}

Background and study aims Endoscopic management using standard accessories is the preferred modality for treatment of benign biliary strictures. However, with difficult strictures, there is frequently failure of endoscopic therapy. We are reporting our experience regarding use of a standard diathermic dilator (cystotome) to aid in stricture dilatation and stent placement in patients with difficult strictures.

Patients and methods Data were analyzed from January 2014 to January 2017 at a single tertiary care center in North India. Total 25 patients were included.

Results The mean age was 45 years (varying from 38-55 years). Of the 25 patients with difficult strictures, 14 (56\%) were male and 11 (44\%) were female. Further, of these, 19 had biliary and 6 had pancreatic strictures. The average time of diathermic current application was 3.5 seconds (ranging 3-5 seconds). Technical and clinical success were achieved in $100 \%$ of cases. None of the patients had any procedure-related (early or delayed) major complications. Conclusion The cystotome is an extremely safe and useful accessory in benign biliary and pancreatic strictures, whereas conventional methods to negotiate stricture have failed.

\section{Introduction}

Endoscopic management has been the preferred modality for treatment of benign biliary and pancreatic ductal strictures. Standard treatment includes trans-papillary cannulation of the desired duct during endoscopic retrograde cholangiopancreatography (ERCP), passing a guidewire across the stricture, dilation if necessary using balloon catheters, and finally placement of single/coaxial multiple plastic stents or covered metal stents, depending upon the indication for ductal drainage [1]. However, in difficult and severe strictures such as post-live-donor liver transplant (LDLT) biliary strictures, after placement of a guidewire, the passage of accessories across the stricture is not feasible, resulting in failure of the therapy [2]. In such difficult situations, wherein all the standard accessories and conventional methods had failed, we used a standard diathermic dilator (cystotome) to aid in stricture dilatation and stent placement.

Herein, we describe the technique and our experience with this novel method of addressing a common problem.

\section{Patients and method}

The current experience is based on a single-center, retrospective analysis of patients who underwent therapeutic endoscopic retrograde cholangiopancreatography (ERCP) with cystotome between January 2014 and January 2017, for difficult biliary and pancreatic stricture management. The protocol for retrospective analysis was approved by the institute's review board/ethical committee.

A cohort of difficult, benign biliary and pancreatic strictures was studied. Difficult strictures were defined as those strictures 
where, subsequent to a guidewire placement across the stricture, none of the standard accessories including a standard cannula, sphincterotome, taper tip sphincterotome, biliary dilation balloon, and pancreatic dilator, succeeded in crossing the stricture over the guidewire. Such strictures comprised the focus of the current study and were subjected to the method described below.

Two experienced endoscopists (R.P. and R.S.) did all ERCPs over the study period. All patients were studied for technical success of the procedure, checked for immediate or late complications and followed up for 6 months for the final outcomes of the procedure.

All patients aged $>18$ years with defined difficult biliary and pancreatic stricture were included in the analysis, after obtaining informed consent. Exclusion criteria were age $<18$ years, pregnancy, coagulopathy (international normalized ratio [INR] $>1.5$, platelets $<50,000 / \mathrm{cm}$ ), and malignant stricture. Anticoagulant and antiplatelet agents were withheld 5 days before the procedure (in 3 patients).

\section{Endoscopic equipment and diathermic technique}

All ERCPs were performed using a standard duodenoscope (CLV 190, Olympus Inc., Japan). Standard accessories such as sphincterotome (Boston Scientific Inc., Massachusetts, United States) and guidewires (0.025/0.035 straight/angled tip, VisiGlide, Olympus Inc., Japan) were used for cannulation and stricture access. All the strictures were negotiated across with guidewires under fluoroscopic guidance, as is done during standard ERCP. In serial attempts at negotiation of the strictures, a standard sphincterotome/cannula, was used and failing that, a tapered-tip cannula/sphincterotome or biliary dilation balloon catheter (Hurricane RX, Boston Scientific, Massachusetts, United States) or a tapered-tip pancreatic dilator (GGDC-7-5-4, Cook medical) was used.

In cases where all the above-mentioned standard accessories and methods failed, a $6 \mathrm{Fr}$ cystotome with diathermic metal tip (Cysto Gastro-Set; Endo-Flex, Voerde, Germany) was passed over the guidewire up to the level of biliary or pancreatic stricture, under fluoroscopic guidance. The stricture was then negotiated using diathermic electrocautery (EC) current using EC generator (ERBE vio 200). The settings were standard sphincterotomy, kept at Endo-Cut I (Monopolar, forced coagulation, Effect-2, Coag 55 watts) mode. The current was applied until the tip of the cystotome crossed the stricture. The current application was subsequently stopped and the cystotome was advanced further across the stricture. Thereafter, the stricture was further dilated using standard procedure with a biliary balloon and stented as in a conventional standard procedure.

Technical and clinical success were defined as successful negotiation of biliary/pancreatic strictures with cystotome and subsequent stenting, establishing ductal drainage. Adverse events were defined as per American Society of Gastrointestinal Endoscopy (ASGE) guidelines [2].

All patients were monitored in hospital for 24 hours for immediate post-procedure complications and were followed up for 6 months for delayed complications. Patients undergoing

\begin{tabular}{|l|l|}
\hline \begin{tabular}{|l|}
\hline Table 1 Patients characteristics. \\
\hline Total no. of cases
\end{tabular} & 25 \\
\hline - Males & $14(60 \%)$ \\
\hline - Females & $11(40 \%)$ \\
\hline Age & 45 years (mean); range $38-55$ \\
\hline Biliary strictures & 18 \\
\hline - Post-LDLT & 15 \\
\hline - Post-cholecystectomy & 4 \\
\hline Location of biliary strictures & \\
\hline - Segmental & 12 \\
\hline - Hepatic duct & 2 \\
\hline - CBD & 5 \\
\hline Pancreatic strictures & 6 \\
\hline - Chronic pancreatitis & 6 \\
\hline Location of pancreatic strictures & 6 \\
\hline - Pancreatic head & 6 \\
\hline LDLT, live-donor liver transplant; CBD, common bile duct \\
\hline
\end{tabular}

further procedures for stent exchange and/or upsizing of stents underwent this procedure using standard accessories.

\section{Results}

Of the 3,342 therapeutic ERCPs (Biliary-2024 and Pancreatic1318) done at our center during the study period, strictures were encountered in 912 cases. Of the 912 strictures, 596 were benign, 416 were biliary and 180 were pancreatic. Cystotome-guided access was used in a total of 25 cases (biliary 19, pancreatic 6). Of the biliary strictures, 15 were post-LDLT anastomotic biliary strictures and four were post-cholecystectomy bile duct strictures. Of these, 12 patients had a stricture at the segmental level, in two patients, it was at the hepatic duct level, and five patients had the stricture in the common bile duct. All six patients with pancreatic strictures had chronic pancreatitis with stricture in the pancreatic head.

There were $14 / 25$ males (56\%) and $11 / 25$ females (44\%) with mean age of 45 years (range $38-55$ years) ( $\downarrow$ Table 1 ).

Cystotome-guided access was required only once in all patients and subsequent sessions were carried out using standard accessories.

The average time of diathermic current application was 3.5 seconds (range $3-5$ seconds).

Technical and clinical success were achieved in all 25 patients. All patients were stented using single or coaxial plastic stents/covered metal stents (in 3 post-cholecystectomy biliary strictures) (\ Fig. 1).

Of the 25 patients, 15 (60\%) complained of post-procedure mild upper abdominal discomfort, which subsided after taking oral analgesics. None of the patients had any major post-proce- 

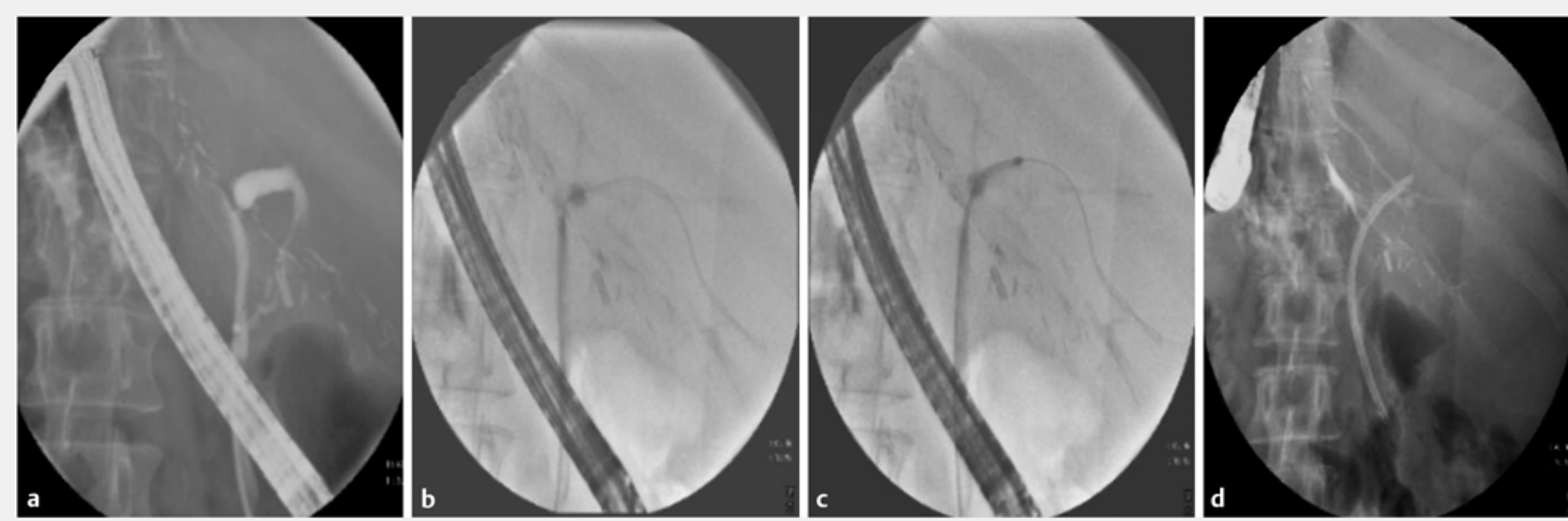

Fig. 1 Wire-guided cystotome access, dilatation and stenting of a difficult anastomotic biliary stricture in a case of live-donor liver transplant (LDLT).

- Table 2 Outcome of wire-guided cystotome dilatation of biliary and pancreatic strictures.

\begin{tabular}{|l|c|}
\hline Technical success & $25(100 \%)$ \\
\hline Biliary strictures & \\
\hline - Plastic stents placed & 16 patients \\
\hline - Covered metal stents placed & 3 patients \\
\hline - 6-month follow-up of remodeled strictures & 12 patients \\
\hline Pancreatic strictures & \\
\hline - Plastic stents placed & 6 patients \\
\hline - 6-month follow-up of remodeled strictures & 5 patients \\
\hline
\end{tabular}

dure complications. There were also no major complications reported during the 6-month follow-up period ( $\triangleright$ Table 2 ).

\section{Discussion}

Biliary and pancreatic strictures are usually symptomatic and are routinely successfully managed with ERCP-guided endoscopic stenting [1]. Failure to dilate the stricture using the standard accessories after successful placement of a guidewire across the stricture is a common and frustrating problem for endoscopists. A very tight stricture precludes passage of even the most stiff and tapered accessories, and all attempts to advance the assembly fail, as there is no direct transmission of axial force due to buckling of the accessory assembly.

Several techniques previously have been described to bypass this rarely encountered problem. These include using a Soehendra stent removal device as a "screw drill" method to burrow through the stricture [3] and using a needle knife or wire-guided snare tip to cut tight strictures $[4,5]$. The major limitation of these techniques was fear of ductal perforation/leaks and risk of pancreatitis due to pancreatic ductal trauma as these techniques were not truly coaxial to the guidewire. In addition, ma- nipulation of snare tip/needle knife tip as a blind technique is technically difficult and carries a high risk of ductal perforation and creation of a false passage [6].

Kawakami et al successfully described use of a diathermy dilator for access and dilation of difficult biliary and pancreatic strictures in a limited case series [7,8].

The cystotome as an accessory has been described for drainage of pancreatic pseudocysts internally via gastric or duodenal routes and that is where it is still most commonly used [9]. Recently, its use has been extended to endoscopic ultrasound (EUS)-guided pancreatic cyst/necrotic collections drainage, as well as EUS-guided bile duct drainage [10]. For this purpose, routinely, $10 \mathrm{Fr}$ cystotome assemblies are employed to create fistulas between pancreatic cysts and the gastric wall. However, in the current study we used a $6 \mathrm{Fr}$ assembly to aid in narrowcaliber biliary and pancreatic ductal manipulation. None of our patients had any major procedure-related complications. Kawakami et al described hemobilia and mild pancreatitis as complications in their series [8]. However, the said series included malignant strictures as well and hemobilia could possibly have resulted due to increased tumor vascularity. In addition, mild pancreatitis was described in a patient in whom a covered metal stent was placed in the pancreatic duct, thus confounding stent vs. procedure as the causative factor for pancreatitis [8]. We found the procedure to be extremely safe in all pancreatic stricture dilatations without any major sequelae.

The limitations of the study include a small sample size and non-randomized design.

\section{Conclusion}

Overall, we found the cystotome to be an extremely safe and useful accessory in benign biliary and pancreatic strictures wherein conventional methods for negotiating the stricture have failed. Further studies are warranted, especially in malignant and pancreatic strictures, before this technique can be incorporated in standard guidelines for stricture management. 
Competing interests

None

\section{References}

[1] ASGE TechnologyAssessment Committee, Pfau PR, Pleskow DK et al. Pancreatic and biliary stents. Gastrointest Endosc 2013; 77: 319-327

[2] Cotton PB, Eisen GM, Aabakken L et al. A lexicon for endoscopic adverse events: report of an ASGE workshop. Gastrointest Endosc 2010; 71: $446-454$

[3] Faigel DO, Ginsberg GG, Kochman ML. Innovative use of the Soehendra stent retriever for biliary stricture recanalization. Gastrointest Endosc 1996; 44: 635

[4] Gao DJ, Hu B, Pan YM et al. Feasibility of using wire-guided needleknife electrocautery for refractory biliary and pancreatic strictures. Gastrointest Endosc 2013; 77: 752-758
[5] Itoi T, Sofuni A, Itokawa F et al. Transpapillary incision of refractory circumscript pancreatic duct stricture using wire-guided snare forceps. World J Gastroenterol 2010; 16: 1541 -1544

[6] Costamagna G, Boskoski I. Needle-knife electrocautery: "give me a lever and I will move the world”. Gastrointest Endosc 2013; 77: 759760

[7] Kawakami H, Kuwatani M, Eto K et al. Resolution of a refractory severebiliary stricture using a diathermic sheath. Endoscopy 2012; 44: (Suppl. 02): E119-E120

[8] Kawakami H, Kuwatani M, Kawakubo K et al. Transpapillary dilation of refractory severe biliary stricture or main pancreatic duct by using a wire-guided diathermic dilator (with video). Gastrointest Endosc 2014; 79: $338-343$

[9] Cremer M, Deviere J, Baize M et al. New device for endoscopic cystoenterostomy. Endoscopy 1990; 22: 76-77

[10] Mandai K, Uno K, Okada Y et al. Endoscopic ultrasound-guided hepaticogastrostomy using a 6-F cystotome and $12-\mathrm{cm}$ covered metal stent. Endosc Int Open 2016; 4: E287 -E291 